\title{
A Physiological Intensive Control Insulin-Nutrition-Glucose (ICING) Model Validated in Critically Ill Patients
}

\author{
Jessica Lin ${ }^{\mathrm{a}}$, Normy N. Razak ${ }^{\mathrm{b}}$, Christopher G. Pretty ${ }^{\mathrm{b}}$, \\ Aaron Le Compte ${ }^{\mathrm{b}}$, Paul Docherty ${ }^{\mathrm{b}}$, Jacquelyn D. Parente ${ }^{\mathrm{b}}$, \\ Geoffrey M. Shaw ${ }^{c}$, Christopher E. Hann ${ }^{b}$, J. Geoffrey Chase ${ }^{b}$ \\ ${ }^{a}$ Department of Medicine, University of Otago Christchurch, New Zealand \\ ${ }^{b}$ Center for Bioengineering, University of Canterbury, New Zealand \\ ${ }^{c}$ Department of Intensive Care Medicine, Christchurch Hospital, New Zealand
}

\begin{abstract}
Intensive insulin therapy (IIT) and tight glycaemic control (TGC), particularly in intensive care units (ICU), are the subjects of increasing and controversial debate in recent years. Model-based TGC has shown potential in delivering safe and tight glycaemic management, all the while limiting hypoglycaemia. A comprehensive, more physiologically relevant Intensive Control Insulin-Nutrition-Glucose (ICING) model is presented and validated using data from critically ill patients. Two existing glucose-insulin models are reviewed and formed the basis for the ICING model. Model limitations are discussed with respect to relevant physiology, pharmacodynamics and TGC practicality. Model identifiability issues are carefully considered for clinical settings. This article also contains significant reference to relevant physiology and clinical literature, as well as some references to the modeling efforts in this field.
\end{abstract}

Identification of critical constant population parameters were performed 
in two stages, thus addressing model identifiability issues. Model predictive performance is the primary factor for optimizing population parameter values. The use of population values are necessary due to the limited clinical data available at the bedside in the clinical control scenario. Insulin sensitivity, $S_{I}$, the only dynamic, time-varying parameter, is identified hourly for each individual. All population parameters are justified physiologically and with respect to values reported in the clinical literature. A parameter sensitivity study confirms the validity of limiting time-varying parameters to $S_{I}$ only, as well as the choices for the population parameters. The ICING model achieves median fitting error of $<1 \%$ over data from 173 patients $(\mathrm{N}=42,941$ hrs in total) who received insulin while in the ICU and stayed for $\geq 72 \mathrm{hrs}$. Most importantly, the median per-patient one-hour ahead prediction error is a very low $2.80 \%$ [IQR 1.18, 6.41\%]. It is significant that the $75^{\text {th }}$ percentile prediction error is within the lower bound of typical glucometer measurement errors of $7-12 \%$. These results confirm that the ICING model is suitable for developing model-based insulin therapies, and capable of delivering real-time model-based TGC with a very tight prediction error range. Finally, the detailed examination and discussion of issues surrounding model-based TGC and existing glucose-insulin models render this article a mini-review of the state of model-based TGC in critical care.

Key words: model-based control, tight blood glucose control, TGC, blood glucose, insulin therapy, insulin sensitivity, critical care, predictive performance 


\section{Introduction}

Since the landmark study in surgical intensive care unit (ICU) patients by Van Den Berghe et al. [1], which reduced mortality 18-45\% using tight glycaemic control (TGC), the attitude towards tolerating hyperglycaemia in critically ill patients has changed. Hyperglycaemia worsens outcomes, increasing the risk of severe infection [2], myocardial infarction [3], and critical illnesses such as polyneuropathy and multiple organ failure [1]. However, repeating these results has been difficult, and thus the role of tight glyceamic control during critical illness and suitable glycaemic ranges have been under scrutiny in recent years $[4,5,6,7,8,9,10,11]$. However, conclusions are varied with both success $[1,12,13,14]$, failure, [15] and, primarily, no clear outcome $[16,17,18,19,20,21]$.

Although it is now becoming an unacceptable practice to allow excessive hyperglycaemia and its associated effects [8, 22, 23, 24], moderately elevated blood glucose levels are tolerated or recommended [11] because of the fear of hypoglycaemia and higher nursing effort frequently associated with TGC [8, 10, 25, 26]. Interestingly, some TGC studies that reported a mortality reduction also had reduced and relatively low hypoglycaemic rates $[13,14]$, whereas almost all other reports had increased and often excessive hypoglycaemia $[15,17]$. Finally, model-based and model-derived TGC methods have shown the ability to provide very tight control with little or no hypoglycaemia $[13,27,28,29,30]$.

Many studies have developed glucose-insulin models with varying degrees of complexity for a wide range of uses, primarily in research studies of insulin sensitivity $[27,31,32,33,34,35,36]$. A more comprehensive model review 
can be found in [28]. For a model to be successful in delivery of TGC, it needs to reflect observable physiology, as well as known biological mechanisms. In addition, it should be uniquely identifiable, and the type and number of parameters to be identified should reflect the clinically available data that will provide validation. Finally, the most important aspect for a model to be used in model-based TGC is its predictive ability, where most studies provide only fitting error as validation [29, 33, 36, 37].

This paper presents a more comprehensive model, ICING (Intensive Control Insulin-Nutrition-Glucose model), for the use of glycaemic control particularly in the ICU. The model addresses several incomplete or implicit physiological aspects from prior models by Chase et al. [27] and Lotz et al. [38]. Model limitations are discussed with respect to physiology, pharmacodynamics and TGC practicality. Model identifiability issues are carefully considered for clinical settings. The ICING model is validated using clinical data from critically ill patients and assessed for both its fitting, and more critically for TGC, predictive performance. Finally, issues surrounding TGC and existing glucose-insulin models are extensively reviewed and discussed.

\section{Glucose-Insulin Physiology Model}

Two clinically validated glucose-insulin physiology models set the basis of this study. Both models share the same basic structure of the Minimal Model [32]. The model from Chase et al. [27] was developed and validated for glycaemic level management in the ICU. This model captures the fundamental dynamics seen in critically ill patients, yet has a relatively simple mathematical structure enabling rapid identification of patient-specific parameters 
[39]. This model only requires measurements in blood glucose levels (BG), therefore it can be used by the bedside for clinical real-time identification and control. This structure has been widely used in clinical TGC studies and other analyses [30, 40, 37].

The second model from Lotz et al. [38] was developed for diagnosis of insulin resistance. The modeled insulin sensitivity has high correlation to the euglycaemic hyperinsulinemic clamp (EIC) and high repeatability [38, 41]. This model has more patient specific parameters, but is not suitable for realtime patient-specific parameter identification because it also requires nonreal-time plasma insulin and C-peptide assays [42]. Recent work has sought to eliminate this issue in healthy subjects, but at a loss of precision [43].

\subsection{Critical Care Glucose-Insulin Model (ICU Model)}

Equations (1)-(5) presents the model used for glycaemic control in intensive care from Chase et al. [27], hereafter referred to as the "ICU Model".

\section{ICU Model}

$$
\begin{aligned}
\dot{G} & =-p_{G} G(t)-S_{I}\left(G(t)+G_{E}\right) \frac{Q(t)}{1+\alpha_{G} Q(t)}+\frac{P(t)}{V_{G}} \\
\dot{Q} & =-k Q(t)+k I(t) \\
\dot{I} & =-\frac{n I(t)}{1+\alpha_{I} I(t)}+\frac{u_{e x}(t)}{V_{I}} \\
P\left(t_{i}<t<t_{i+1}\right) & =\bar{P}_{i+1}+\left(P\left(t_{i}\right)-\bar{P}_{i+1}\right) e^{-k_{p d}\left(t-t_{i}\right)} \quad \text { where } \bar{P}_{i+1}<P\left(t_{i}\right) \\
P\left(t_{i}<t<t_{i+1}\right) & =\bar{P}_{i+1}+\left(P\left(t_{i}\right)-\bar{P}_{i+1}\right) e^{-k_{p r}\left(t-t_{i}\right)} \quad \text { where } \bar{P}_{i+1}>P\left(t_{i}\right)
\end{aligned}
$$

The symbols $G[\mathrm{mmol} / \mathrm{L}]$ denotes the glucose above an equilibrium level, 
$G_{E}[\mathrm{mmol} / \mathrm{L}]$. Plasma insulin is $I[\mathrm{mU} / \mathrm{L}]$ and exogenous insulin input is $u_{e x}(t)[\mathrm{mU} / \mathrm{min}]$. The effect of previously infused insulin being utilized over time in the interstitium is represented by $Q[\mathrm{mU} / \mathrm{L}]$, with $k[1 / \mathrm{min}]$ accounting for the effective life of insulin in the system. Patient endogenous glucose removal and insulin sensitivity are $p_{G}[1 / \mathrm{min}]$ and $S_{I}[\mathrm{~L} / \mathrm{mU} / \mathrm{min}]$ respectively. The parameter $V_{I}[\mathrm{~L}]$ is the insulin distribution volume and $n[1 / \mathrm{min}]$ is the constant first order decay rate for insulin from plasma. External nutrition is $P(t)[\mathrm{mmol} / \mathrm{min}]$. In Equations $(4)-(5), k_{p r}[1 / \mathrm{min}]$ and $k_{p d}[1 / \mathrm{min}]$ are the rise and decay rates of exogenous (enteral) plasma glucose appearance, and $\bar{P}_{i}$ and $\bar{P}_{i+1}$ are the stepwise consecutive enteral glucose feed rates used to model dextrose control. The glucose distribution volume is $V_{G}$ [L]. Michaelis-Menten functions are used to portray saturations, with parameter $\alpha_{I}[\mathrm{~L} / \mathrm{mU}]$ used for saturation of plasma insulin disappearance, and $\alpha_{G}[\mathrm{~L} / \mathrm{mU}]$ for saturation of insulin-stimulated glucose removal.

This model was developed and validated in critical care glycaemic control studies $[27,36,37,44]$. All the compartmental transport and utilisation rates are treated as constants except insulin sensitivity $S_{I}$. Insulin sensitivity $S_{I}$ is the critical dynamic parameter, and is typically fitted to patient data hourly, producing a step-wise hourly varying profile. The SPRINT glycaemic control protocol $[13,45,46]$ was developed using this model. Importantly, the pre-trial virtual trial simulation of SPRINT gave very similar results to the subsequent actual clinical implementation results [27], providing a further measure of validation.

However, this model does not realistically describe the gastric uptake of glucose. Equations (4) and (5) express simple exponential rises and decays of 
glucose absorption, which eventually reach a steady state equal to the feeding rate. This simple expression works well in critical care where nasogastric feeding rate is not adjusted frequently. If the feeding rate is changed more frequently than once every 2 hours, Equations (4) and (5) fail to describe the gastric absorption correctly.

This model also employs an "equilibrium blood glucose level" term, $G_{E}$, which is usually set to either the patient's blood glucose level at the start of insulin therapy or a long moving average. This term effectively addresses the endogenous balance of glucose and insulin. Hence, this model does not explicitly express endogenous insulin production. Thus, when there is a significant shift in this balance in a patient, for any number of reasons [36, 44, 47], $G_{E}$ often needs to be adjusted to capture the patient's (then) current clinical glucose-insulin dynamics. Hence, the term is non-physiological, unidentifiable and was ignored in later model evolutions [30, 48, 49].

This model also has relatively simple insulin kinetics compared to other more extensive models $[50,51,52,53]$. It does not explicitly express different routes of insulin clearance and transport from plasma. Instead, the lumped out-flux from plasma is expressed by a saturable term $-n I /\left(1+\alpha_{I} I\right)$. In addition, as only $k I$ appears as an input to interstitial insulin $Q$, the difference between $n$ and $k$ is implicitly the insulin clearance by liver and kidneys, which was validated in Lotz et al. [41]. The insulin flux between plasma and interstitial is also only one way in this model, ignoring the diffusion from interstitium back to plasma, as it was designed for TGC using IV insulin boluses. Therefore, the insulin concentration gradient between plasma and the interstitium using bolus delivery is generally large enough that diffusion 
back to plasma is negligible. However, the use of boluses is less typical in general clinical settings and neglecting diffusion can introduce error in either case.

\subsection{Glucose-Insulin Model for Insulin Sensitivity Test ( $S_{I}$ Test Model)}

Equations (6)-(8) presents the model used for insulin sensitivity testing from Lotz et al. [38], hereafter referred to as the " $S_{I}$ Test Model".

$S_{I}$ Test Model

$$
\begin{aligned}
\dot{G}= & -p_{G} G(t)-S_{I}\left(G(t)+G_{E}\right) \frac{Q(t)}{1+\alpha_{G} Q(t)}+\frac{P(t)}{V_{G}}+E G P(t) \\
\dot{Q}= & \frac{n_{I}}{V_{Q}}(I(t)-Q(t))-n_{C} Q(t) \\
\dot{I}= & -n_{K} I(t)-\frac{n_{L} I(t)}{1+\alpha_{I} I(t)}-\frac{n_{I}}{V_{P}}(I(t)-Q(t))+\frac{u_{e x}(t)}{V_{P}} \\
& +\left(1-x_{L}\right) \frac{u_{e n}(t)}{V_{P}}
\end{aligned}
$$

The nomenclature for this model is largely the same as that for the ICU Model in Section 2.1. This model has more parameters and more extensive insulin kinetics. It includes the endogenous glucose production rate EGP $[\mathrm{mmol} / \mathrm{L} / \mathrm{min}]$, as well as the endogenous insulin production $u_{e n}[\mathrm{mU} / \mathrm{min}]$. The endogenous insulin production can be calculated from C-peptide measurements using a well validated insulin-C-peptide kinetics model [54]. Endogenous insulin goes through first pass hepatic extraction, where $x_{L}$ is the fraction of extraction. This model also has more explicitly defined physiologically specific insulin transport parameters compared to the 
ICU Model, where $n_{K}$ is the kidney clearance rate of insulin from plasma $[1 / \mathrm{min}], n_{L}$ is the liver clearance rate of insulin from plasma $[1 / \mathrm{min}], n_{I}$ is the diffusion constant of insulin between compartments [L/min], and $n_{C}$ is the cellular insulin clearance rate from interstitium $[1 / \mathrm{min}]$. Finally, it also uses different volumes for each compartment, where $V_{P}$ is the plasma volume (+Fast exchanging tissues) [L] and $V_{Q}$ is the interstitial fluid volume [L]. The experimental $V_{P}$ and $V_{Q}$ are however very close [38].

In $[38,42]$, measurements from insulin and C-peptide are used to identify $n_{L}$ and $x_{L}$ for each person. $S_{I}$ and $V_{G}$ are then calculated for each person using BG measurements. All other parameters are treated as population constants. The insulin sensitivity $S_{I}$ identified using this model correlates highly ( $\mathrm{r}>0.97$ ) to EIC results $[38,41]$. Therefore, this model is effective as a diagnostic tool for insulin resistance. However because plasma insulin and C-peptide measurements cannot be obtained in real time, this model cannot be readily adapted for TGC for ICU patients.

\subsection{Intensive Control Insulin-Nutrition-Glucose Model (ICING Model)}

The new and more physiologically comprehensive model developed from the best aspects of both models $[27,38]$ is defined:

$$
\begin{aligned}
\dot{B G}= & -p_{G} B G(t)-S_{I} B G(t) \frac{Q(t)}{1+\alpha_{G} Q(t)}+\frac{P(t)+E G P_{b}-C N S}{V_{G}}(9) \\
\dot{Q}= & n_{I}(I(t)-Q(t))-n_{C} \frac{Q(t)}{1+\alpha_{G} Q(t)} \\
\dot{I}= & -n_{K} I(t)-\frac{n_{L} I(t)}{1+\alpha_{I} I(t)}-n_{I}(I(t)-Q(t))+\frac{u_{e x}(t)}{V_{I}} \\
& +\left(1-x_{L}\right) \frac{u_{e n}}{V_{I}}
\end{aligned}
$$




$$
\begin{aligned}
\dot{P} 1 & =-d_{1} P 1+D(t) \\
\dot{P} 2 & =-\min \left(d_{2} P 2, P_{\max }\right)+d_{1} P 1 \\
P(t) & =\min \left(d_{2} P 2, P_{\max }\right)+P N(t) \\
u_{e n}(t) & =k_{1} e^{-\frac{I(t)^{k_{2}}}{k_{3}}} \text { when C-peptide data is not available }
\end{aligned}
$$

The nomenclature for this model is largely the same as defined in Sections 2.1 and 2.2. However, "equilibrium blood glucose level" $G_{E}$ is no longer present, and $B G(t)$ is the absolute BG level per more recent works $[55,30,48]$. A constant "basal" endogenous glucose production term $E G P_{b}[\mathrm{mmol} / \mathrm{min}]$, which is the endogenous glucose production rate for a patient receiving no exogenous glucose or insulin, is thus added. This model has an additional insulin independent [56] central nervous system glucose uptake, CNS, with an experimental value between $0.29-0.38 \mathrm{mmol} / \mathrm{min}[56,57,58,59,60,61$, $62,63,64]$.

In Equation (9), insulin independent glucose removal (excluding central nervous system uptake $C N S$ ) and the suppression of endogenous glucose production from $E G P_{b}$ with respect to $B G(t)$ are compounded and represented by $p_{G}$. Insulin mediated glucose removal and the suppression of EGP from $E G P_{b}$ are similarly compounded and represented by $S_{I}$. Consequently, $S_{I}$ effectively represents the whole-body insulin sensitivity, which includes tissue insulin sensitivity and the action of Glucose Transporter-4 (GLUT-4). The action of GLUT-4 is associated with the compounding effect of receptor- 
binding insulin and blood glucose, and its signaling cascade is also dependent on metabolic condition and can be affected by medication [65, 66, 67, 68]. Therefore, $S_{I}$ is time varying and can reflect evolving patient condition. Its variation through time can be significant, particularly for highly dynamic, critically ill patients $[40,37]$.

Equations (10) and (11) define the insulin pharmacokinetics similarly to [38] and Equations (7)-(8). Insulin clearance from plasma is saturable, as well as its degradation after receptor binding in the interstitium [69]. The receptor-bound insulin $Q /\left(1+\alpha_{G} Q\right)$ is also the insulin effective for glucose removal to cells. Hence this term also appears in Equation (9) for glucose dynamics. Note that $n_{I}$ in Equations (10) and (11) has unit $[1 / \mathrm{min}]$ rather than $[\mathrm{L} / \mathrm{min}]$ as in Equations (7) and (8). This is because the new model in Equations (9)-(15) does not use different volumes for plasma and interstitial insulin distribution, since the experimental values are very similar in [38, 70]. To compare and convert $n_{I}$ from Lotz el al., its value needs to be divided by $V_{P}$ from Lotz et al.

Equations (12)-(14) present the gastric absorption of glucose, where $P 1[\mathrm{mmol}]$ represents the glucose in the stomach and $P 2[\mathrm{mmol}]$ is for the gut. Transport rates between the compartments are $d_{1}[1 / \mathrm{min}]$ and $d_{2}[1 / \mathrm{min}]$. Amount of dextrose from enteral feeding is $D(t)[\mathrm{mmol} / \mathrm{min}]$. Glucose appearance, $P(t)[\mathrm{mmol} / \mathrm{min}]$ from enteral food intake $D(t)$, is the glucose flux out of the gut $P 2$. This flux is saturable, and the maximal out flux is $P_{\max }=6.11[\mathrm{mmol} / \mathrm{min}]$. Typically, for ICU patients on enteral feeding, $P_{\max }$ is not reached. Any additional parenteral dextrose is represented by $P N(t)$. This dextrose absorption model conserves ingested glucose, and 
therefore is also suitable for modeling meal ingestion over a short period of time in contrast to the simpler model of Equations (4) and (5).

Equation (15) is a generic representation of endogenous insulin production when C-peptide data is not available from the patient for specific identification of its production. Endogenous insulin production, with the base rate being $k_{1}[\mathrm{mU} / \mathrm{min}]$, is suppressed with elevated plasma insulin levels. The exponential suppression is described by generic constants $k_{2}$ and $k_{3}$.

\section{Model Validation Methods}

Validation of the glucose-insulin model presented in Equations (9)-(14) is performed using data from 173 patients (42,941 total hours) that were on the SPRINT TGC protocol [13] for 3 or more days, which also had a statistically significant hospital mortality reductions. These patients also had long enough stays to exhibit periods of both dynamic evolution and metabolic stability. The median APACHE II score for this cohort is 19 [IQR 16, 25] and the median age is 64 [IQR 49,73] yrs old. The percentage of operative patients is $33 \%$.

Insulin sensitivity, $S_{I}$ is the critical patient specific parameter that is fitted hourly to clinical blood glucose measurements using an integral-based fitting method [39]. The rest of the parameters are kept as population constants. This approach was verified for the ICU model via a sensitivity study [39]. (A sensitivity study is also performed in this study for the ICING model see Section 3.4). The model is assessed for its accuracy by fitting errors, as well as robustness, or adaptability, by prediction errors. Fitting error is

simply the error between the measured and the modelled blood glucose levels. 
When an hourly $S_{I}$ is identified, a prediction of blood glucose level in one hour using this identified $S_{I}$ is also made given the clinical record of insulin and nutrition support. The prediction error is then the error between the prediction and the actual blood glucose level.

Intra- and inter-patient variability are examined by looking at the data on a by-cohort or per-patient basis. By-cohort analysis looks at the statistics on all the available hourly fitting and prediction errors (weighting each hour equally), whereas per-patient analysis looks at the statistics on each individual patient (weighting each patient equally).

Essentially the model improvements from the ICU model to the ICING model are made in two stages: firstly on the glucose compartment, secondly on the insulin pharmacokinetics. During each stage, the important population constant parameters are optimised using grid-search methods. The grid-search approach is robust to measurement noise and can provide an assessment of parameter sensitivity.

During the first stage of improvements on the glucose compartment, $E G P_{b}$ and $p_{G}$ are optimised as a pair. The insulin pharmacodynamics are kept as in Equations (2)-(3) during this stage - as the constant parameters in Equations (10)-(11) are yet to be optimised. In the second stage of model improvement, the ICING model takes its complete form and the constant insulin pharmacokinetics parameters are optimised. Finally a re-assessment of $p_{G}$ and $E G P_{b}$, as well as a parameter sensitivity using the completed ICING model are performed. 


\subsection{Identification of $p_{G}$ and $E G P_{b}-$ Stage 1}

In the first stage of model improvement, $p_{G}$ and $E G P_{b}$ are optimised as a pair. Constant parameter values used in this stage of parameter identification can be seen in Table 1. These constant parameters are consistent with values found in surveys of population studies [36, 37, 55], and have been verified for their suitability of being set to population constants in a previous parameter sensitivity study [39] and clinical glycaemic control studies [30, 36, 44, 48].

The range of the grid search covers $p_{G}=0.001 \rightarrow 0.1[1 / \mathrm{min}]$ with increments of 0.001 , and $E G P_{b}=0.0 \rightarrow 3.5[\mathrm{mmol} / \mathrm{min}]$ with increments of 0.1 . Fitting and prediction errors are calculated for each $p_{G}, E G P_{b}$ coordinate for each patient to find the optimal combination.

\subsection{Identification of Insulin Kinetics Parameters - Stage 2}

Model improvements on Insulin pharmacokinetics are made in the second stage, and the model takes its final form as defined in Equations (9)-(15). Parameters associated with insulin kinetics are identified in this stage. Lotz et al. [38] uses measurements from insulin and C-peptide to identify patient specific liver clearance $n_{L}$ and first pass endogenous insulin hepatic uptake $x_{L}$ in Equations (7)-(8). The value for kidney clearance, $n_{K}$, was taken from a well validated population model of C-peptide kinetics, and the transcapillary diffusion rate $n_{I}$ was calculated by a method proposed by the same authors [54]. For this study, ICU patient data does not contain the insulin measurements to allow for unique identification of $n_{L}$ and $x_{L}$. However, the transition from Equations (2) and (3) to Equations (10) and (11) makes $n_{I}$ the critical parameter to be investigated. 
Table 1: Models and constant parameter values and/or ranges

\begin{tabular}{|c|c|c|c|}
\hline $\begin{array}{c}\text { Constant } \\
\text { Parameters }\end{array}$ & $\begin{array}{c}I C U \\
\text { Model [27] }\end{array}$ & $\begin{array}{c}S_{I} \text { Test } \\
\text { Model [38] }\end{array}$ & $\begin{array}{c}\text { ICING } \\
\text { Model (Final) }\end{array}$ \\
\hline$G_{E}[\mathrm{mmol} / \mathrm{L}]$ & starting $\mathrm{BG}^{*}$ & starting $\mathrm{BG}^{*}$ & - \\
\hline$C N S[\mathrm{mmol} / \mathrm{min}]$ & - & - & 0.3 \\
\hline$\alpha_{G}[\mathrm{~L} / \mathrm{mU}]$ & 0.0154 & 0 & 0.0154 \\
\hline$V_{G}[\mathrm{~L}]$ & 13.3 & $10.00-15.75$ & 13.3 \\
\hline$\alpha_{I}[\mathrm{~L} / \mathrm{mU}]$ & 0.0017 & 0.0017 & 0.0017 \\
\hline$n[1 / \mathrm{min}]$ & 0.16 & - & - \\
\hline$k[1 / \mathrm{min}]$ & 0.0198 & - & - \\
\hline$p_{G}[1 / \mathrm{min}]$ & 0.01 & 0.01 & to be identified \\
\hline$E G P_{b}[\mathrm{mmol} / \mathrm{min}]$ & - & - & to be identified \\
\hline$n_{I}$ & - & $0.21-0.36[\mathrm{~L} / \mathrm{min}]$ & to be identified $[1 / \mathrm{min}]$ \\
\hline$n_{C}[1 / \mathrm{min}]$ & - & $0.032-0.033$ & $=n_{I}$ \\
\hline$n_{L}[1 / \min ]$ & - & $0.10-0.21$ & 0.1578 \\
\hline$n_{K}[1 / \mathrm{min}]$ & - & $0.053-0.064$ & 0.0542 \\
\hline$x_{L}$ & - & $0.50-0.95$ & 0.67 \\
\hline$V_{I}[\mathrm{~L}]$ & 3.15 & - & 3.15 \\
\hline$V_{Q}[\mathrm{~L}]$ & - & $4.44-7.47$ & - \\
\hline$V_{P}[\mathrm{~L}]$ & - & $3.90-5.96$ & - \\
\hline$k_{p r}[1 / \mathrm{min}]$ & 0.0347 & - & - \\
\hline$k_{p d}[1 / \min ]$ & 0.0069 & - & - \\
\hline$d_{1}[1 / \mathrm{min}]$ & - & - & 0.0347 \\
\hline$d_{2}[1 / \min ]$ & - & - & 0.0069 \\
\hline$P_{\max }[\mathrm{mmol} / \mathrm{min}]$ & - & - & 6.11 \\
\hline$k_{1}[\mathrm{mU} / \mathrm{min}]$ & - & - & 45.7 \\
\hline$k_{2}$ & - & 15 & 1.5 \\
\hline$k_{3}$ & - & - & 1000 \\
\hline
\end{tabular}


The interstitial insulin transfer rate, $k$, in Equation (2) was calculated to correspond to the active interstitial insulin half-life [44]. Effectively, Equation (2) thus represents a delay compartment for insulin action in the interstitium, and can be re-written:

$$
Q(t)=k \int_{0}^{t} I(\tau) e^{-k(t-\tau)} d \tau
$$

On the other hand, the analytical solution of $Q$ in Equation (10) is:

$$
Q(t)=n_{I} \int_{0}^{t} I(\tau) e^{-\left(n_{I}+n_{C}\right)(t-\tau)} d \tau
$$

Therefore, the decay rate of interstitial insulin is $n_{I}+n_{C}$ in Equation (10), and this rate should be comparable to $k$ in Equation (2).

Studies indicated that steady state interstitial to plasma insulin ratio is between $0.4-0.6[71,72,73]$. Lotz et al. [38] uses a population value of 0.5 for this ratio. Therefore $n_{I}=n_{C}$ can be assumed from the steady state calculation using Equation (10) provided the steady state $Q$ is low so $Q /\left(1+\alpha_{G} Q\right) \approx Q$

In this study, a grid search of $n_{I}$ is used to obtain a suitable model value. Again, integral fitting is used to identify hourly $S_{I}$. The grid covers $n_{I}=n_{C}=10^{-4} \rightarrow 0.02[1 / \mathrm{min}]$. The fitting and prediction error are calculated at each grid for each patient. Other constant parameter values are listed in Table 1. The value for $n_{K}$ is taken from Van Cauter et al. [54] and $n_{L}$ is the mean fitted value found in Lotz et al. [38, 70]. First pass hepatic insulin uptake, $x_{L}$ was also a fitted parameter in Lotz et al. [38], and is coupled with liver clearance $n_{L}$. In this study, $x_{L}$ is assumed to be 0.67 , which is within the range reported by Lotz et al. [38, 70]. In this study, $x_{L}$ 
has a relatively insignificant role, as patients on intensive insulin therapy can be assumed to have their endogenous insulin production suppressed due to elevated plasma insulin levels. The other constant parameters are kept the same as in the identification of $p_{G}$ and $E G P_{b}$.

\subsection{Re-assessment of $p_{G}$ and $E G P_{b}$}

A re-assessment of the population constant values of $p_{G}$ and $E G P_{b}$ is performed using the complete ICING model. The grid analysis covers $p_{G}=$ $0.005 \rightarrow 0.025[1 / \mathrm{min}]$ and $E G P_{b}=0.5 \rightarrow 2.5[\mathrm{mmol} / \mathrm{min}]$ with an increment step of 0.0033 and 0.33 respectively.

\subsection{Parameter sensitivity analysis}

The robustness of model population parameters $n_{L}, n_{K}, n_{C}$ and $\alpha_{G}$ on the model fit and predictive performance of the ICING model is tested by modifying individual model values (summarized in Table 1) by $\pm 50 \%$. While one parameter is being altered, the rest of the parameters are kept at their original values in Table 1. Changes in model performance can indicate the suitability of their assumed values, and whether or not they should be used as population constants.

\section{Results}

\section{1. $p_{G}$ and $E G P_{b}-$ Stage 1}

The per-patient median fitting and prediction errors over the ranges $p_{G}=0.001 \rightarrow 0.1\left[\mathrm{~min}^{-1}\right]$ and $E G P_{b}=0 \rightarrow 3.5[\mathrm{mmol} / \mathrm{min}]$ are shown in Figure 1. Sub-figures 1(a) and 1(c) show the median of all median 
hourly $\%$ errors for each patient. Sub-figures $1(\mathrm{~b})$ and $1(\mathrm{~d})$ show the median range of the $90 \%$ confidence interval in hourly $\%$ error for each patient. Smaller (tighter) range means tighter distribution with less outliers. In general, lower fitting and prediction errors and error ranges are produced in the lower $p_{G}$ and lower $E G P_{b}$ regions, where the plot is darkest.

Figure 2(a) shows the cumulative distribution function of the prediction error over all available hourly data for the selected $p_{G}$ and $E G P_{b}$ combinations. The performance is very similar for $\left[p_{G}, E G P_{b}\right]=[0.002,0.5],[0.006$, $0.8]$ and $[0.006,1.16]$. However, the predictive performance is significantly worse for $E G P_{b}=2.3 \mathrm{mmol} / \mathrm{min}$, where this value is tested to demonstrate the impact of applying an extreme, supra-physiological value across the entire cohort. In contrast, Figure 2(b) shows the cumulative distribution function of the fitting error for the same combinations of $p_{G}$ and $E G P_{b}$ values. The model clearly delivers the best fitting error with $\left[p_{G}, E G P_{b}\right]=[0.006,1.16]$.

From the figures of prediction and fitting error generated, it can be observed that the best balance between fitting and prediction is achieved by the combination $\left[p_{G}, E G P_{b}\right]=[0.006,1.16]$. Glucose metabolism studies reported $E G P$ values range from $0.91 \rightarrow 1.4[\mathrm{mmol} / \mathrm{min}][48,74,75]$. The value for $E G P_{b}$ identified in this study is therefore physiologically valid. Reported values for $p_{G}$ from studies have been shown to range between $0.004 \rightarrow 0.047$ $\min ^{-1}[32,76,77,78]$. Therefore, the identified $p_{G}=0.006[1 / \mathrm{min}]$ is also physiologically valid.

\subsection{Insulin Kinetics Parameters - Stage 2}

The median of the $25^{\text {th }}, 50^{\text {th }}$ and $75^{\text {th }}$ percentile fitting and prediction errors for each patient across $n_{I}=10^{-4} \rightarrow 0.02 \mathrm{~min}^{-1}$ in the full ICING 


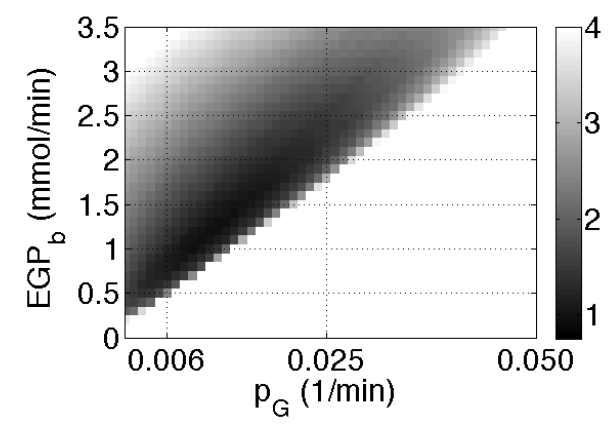

(a) Median \% fitting error

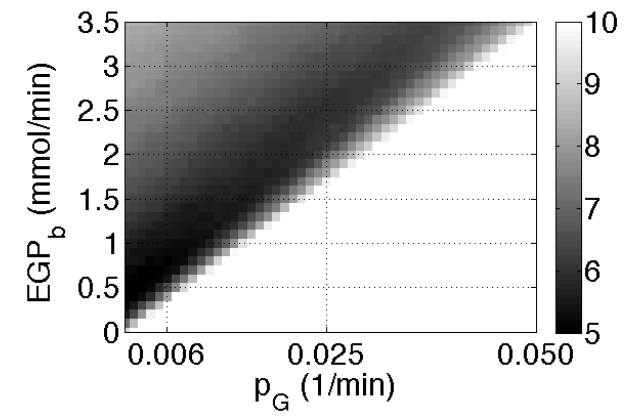

(c) Median $\%$ prediction error

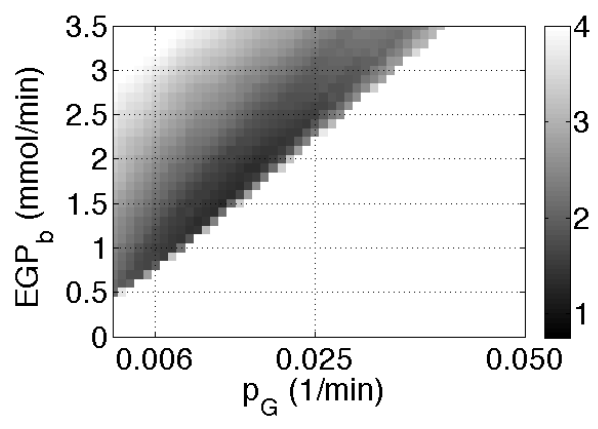

(b) $90 \%$ confidence interval in $\%$ fitting error

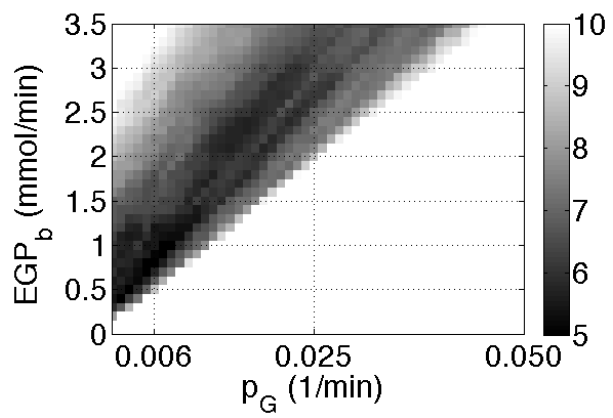

(d) $90 \%$ confidence interval in $\%$ prediction error

Figure 1: Per-patient percentage fitting and prediction error with respect to $p_{G}$ and $E G P_{b}$. Each coordinate plots the median of the results from individual patients. 1(a) and 1(c) show the median of the median hourly $\%$ error for each patient. 1(b) and 1(d) show the median range of the $90 \%$ confidence interval in hourly $\%$ error for each patient. Smaller (tighter) range means tighter distribution with less outliers. 


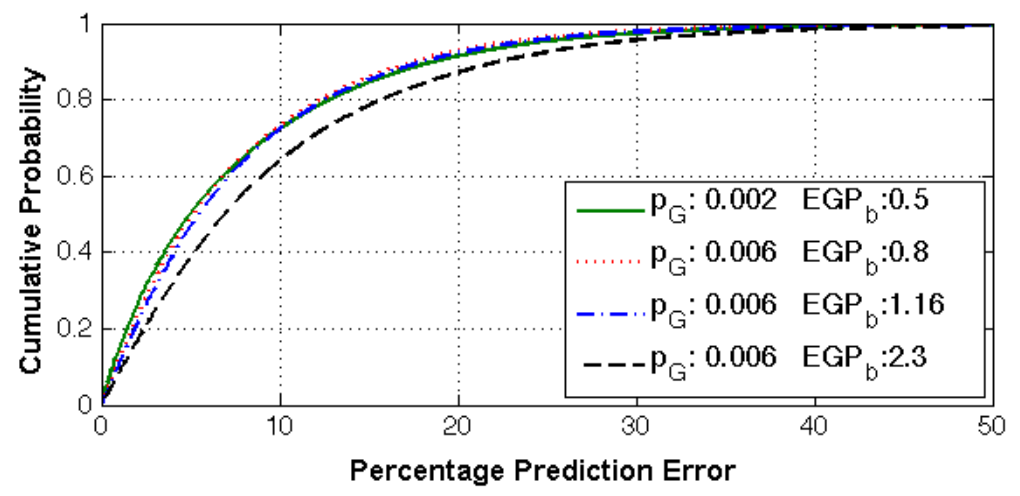

(a) Prediction error (\%)

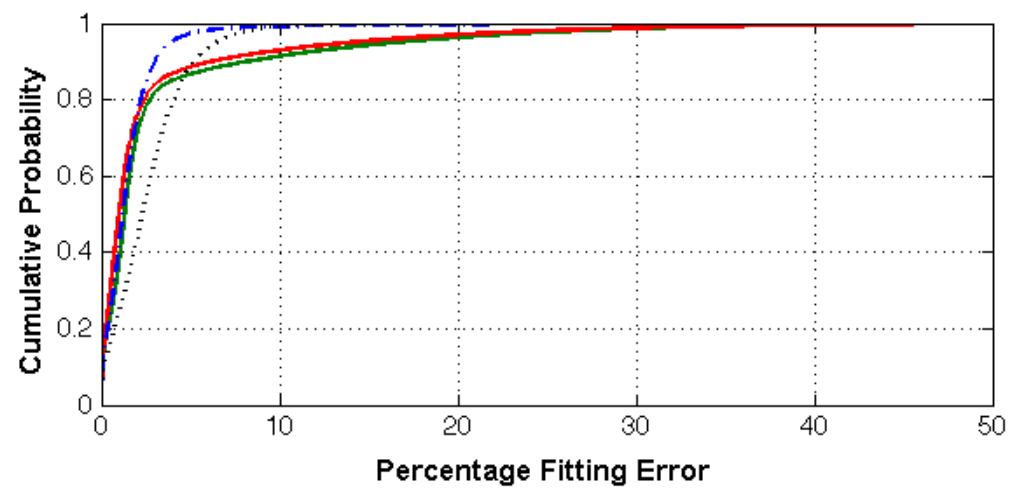

(b) Fitting error (\%)

Figure 2: Cumulative distribution functions (cdf) of by-cohort prediction and fitting errors with different combinations of $p_{G}$ and $E G P_{b}$. Every hourly error contribute to the cdf.

model are shown in Figure 3. It can be seen that $n_{I}=0.003 \mathrm{~min}^{-1}$ provides the best predictive performance while fitting error is low through the entire range.

Patient 5004 is shown in Figure 4 as an example of typical model fit using the fully identified ICING model. The results show the model is capable of capturing the patient's highly variable dynamics during critical illness, 


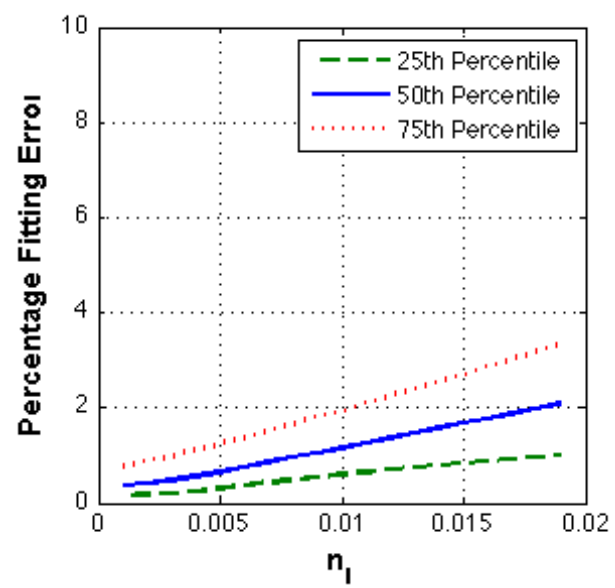

(a) Fitting Error (\%)

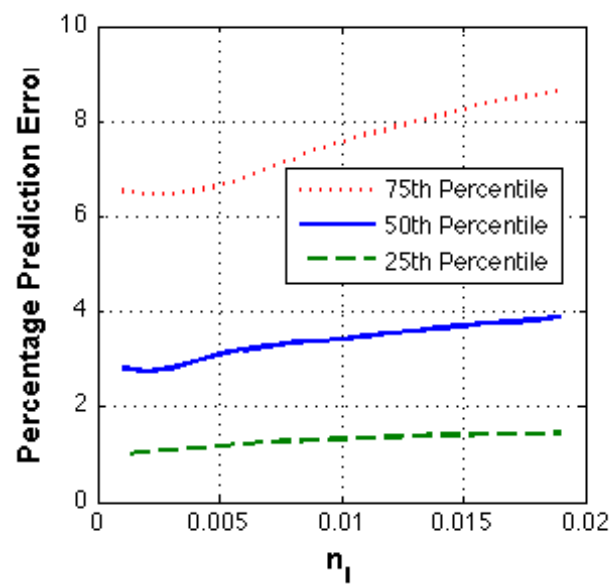

(b) Prediction Error (\%)

Figure 3: Fitting and prediction error from $n_{I}$ grid search.

particularly from the $50^{\text {th }}$ hour to the end of the patient's stay, where the insulin requirement varied significantly from hour to hour.

In Figure 4, only end-of-hour insulin levels in plasma and interstitial are plotted for readability. The response curves from insulin injections plotted by the minute can be seen in Figure 5. The impact of $n_{I}$ on modeled insulin can be seen with two different values used. The receptor bound insulin using $n_{I}=0.0476 \mathrm{~min}^{-1}$ from Lotz et al. [38] peaks and decays a lot faster than having the smaller $n_{I}=0.003 \mathrm{~min}^{-1}$ found in grid search. More importantly, the large $n_{I}$ value does not allow receptor-bound insulin levels to accumulate over time. Applying this large $n_{I}$ value, the model fails to capture a patient's long term glucose-insulin response. The per-patient fitting error also increases to 5.32 [IQR 0.98, 9.70]\% from 2.80 [IQR 1.18, 6.41]\%. More specifically, over $25 \%$ of the hourly modeled BG fails to capture clinical 

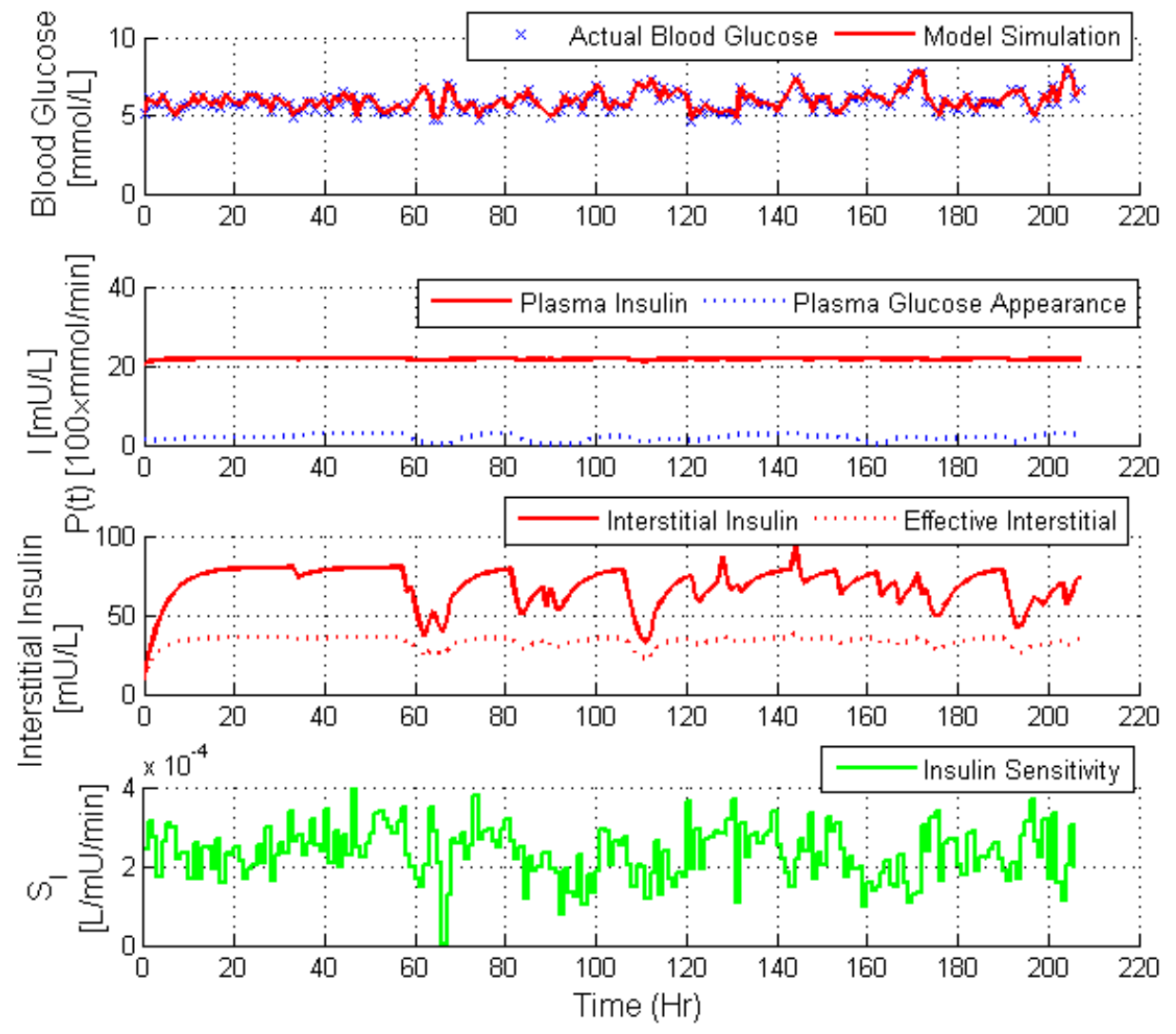

Figure 4: Model simulation results on Patient 5004 using the parameters identified for the ICING model. Only end-of hour data are plotted for readability. In the top panel, the solid line $(-)$ illustrates the blood glucose model simulation while crosses $(\times)$ represents the actual blood glucose measurements. The second panel demonstrates the plasma insulin appearance $(-)$ and plasma glucose appearance $(\cdots)$. The third panel shows the interstitial insulin (-) and the effective (receptor-bound) interstitial insulin ( $\cdots)$. Model fitted insulin sensitivity is displayed in the bottom panel. 
measurements, which typically have a measurement error of $7 \%$.
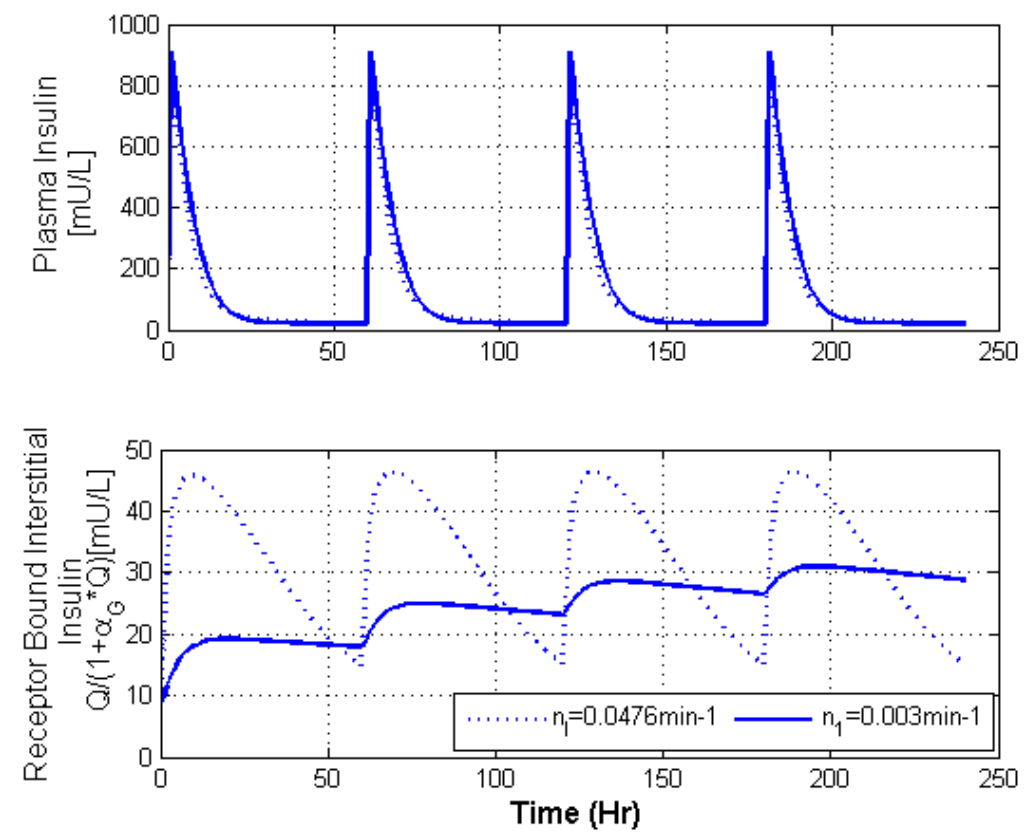

Figure 5: Dose response curves of plasma insulin and receptor bound interstitial insulin from an insulin injection of $3 \mathrm{U}$ at the beginning of each hour.

The improvements in model performance from the the ICU model, through improvements in glucose compartment (Stage 1), and finally the ICING model in Equations (9)-(15) are shown in Table 2. The table shows the median and IQR for absolute percentage model fit and predictive error for the total 42941 hours of clinical data from 173 patients. Results are shown on both per-patient and by cohort basis to highlight any inter- and intra-patient variability in model performance.

The final model achieved improvements in performance compared to the 
ICU model in Equations (1)-(5). The predictive ability of the ICING model improved significantly with much lower median prediction errors. More importantly, the spread of error is tighter, evident by a much lower upper quartile ( $75^{\text {th }}$ percentile) error, which is now within measurement error for both by-cohort and per-patient results. The main reduction is in the upper quartile cohort prediction error, which is reduced to $6.47 \%$ from $10.64 \%$, indicating significantly better management of inter-patient variability in the final model.

Main results in Table 2 show:

1. Improvement in glucose compartment reduces intra-patient variability with lower per-patient upper quartile prediction.

2. Finalised ICING model reduces inter-patient variability with lower upper quartile by-cohort prediction errors.

\subsection{Re-Identification of $p_{G}$ and $E G P_{b}$}

Grid search for the re-identification of $p_{G}$ and $E G P_{b}$ near the previously identified $\left[p_{G}, E G P_{b}\right]=[0.006,1.16]$ from Section 4.1 re-affirm these values. This combination of $p_{G}$ and $E G P_{b}$ values provides very low fitting and prediction errors in the grid search region, and does not require adjustments.

\subsection{Parameter Sensitivity}

The parameter sensitivity study results for $n_{K}, n_{L}, n_{C}$ and $\alpha_{G}$ are shown in Table 3. Changes of $\pm 50 \%$ from their final parameter values for the ICING model in Table 1 have no clinically (as opposed to statistically) significant effect on simulation results in terms of prediction error, fitting error and 
Table 2: Comparison of median and IQR for prediction and fitting error

\begin{tabular}{|c|c|c|c|}
\hline \multicolumn{4}{|c|}{ Prediction Error (\%) median [IQR] } \\
\hline & & Improved Glucose & \\
\hline & Original ICU Model & Compartment & ICING Model \\
\hline Per-Patient\# & $5.90[4.75,7.51]$ & $5.23[4.20,6.36]$ & $2.80[1.18,6.41]$ \\
\hline By Cohort ${ }^{+}$ & $5.59[2.46,10.64]$ & $5.02[2.11,10.34]$ & $2.81[1.08,6.47]$ \\
\hline \multicolumn{4}{|c|}{ Fitting Error $(\%)$ median $[\mathrm{IQR}]$} \\
\hline Per-Patient $\#$ & $1.11[0.84,1.63]$ & $0.86[0.58,1.18]$ & $0.50[0.21,0.99]$ \\
\hline By Cohort ${ }^{+}$ & $1.02[0.41,1.94]$ & $0.71[0.23,1.44]$ & $0.47[0.20,0.97]$ \\
\hline \multicolumn{4}{|c|}{$S_{I}\left(10^{-3} \mathrm{~L} / \mathrm{mU} / \mathrm{min}\right)$ median $[\mathrm{IQR}]$} \\
\hline Per-Patient\# & $0.25[0.11,0.45]$ & $0.21[0.13,0.41]$ & $0.31[0.23,0.40]$ \\
\hline By Cohort ${ }^{+}$ & $0.24[0.14,0.40]$ & $0.21[0.14,0.32]$ & $0.31[0.20,0.48]$ \\
\hline \multicolumn{4}{|c|}{ Per-patient analysis weights each patient equally, indicating inter-patient variabili } \\
\hline \multicolumn{4}{|c|}{+ By-cohort analysis weights each hour of data equally, indicating intra-patient } \\
\hline
\end{tabular}

identified insulin sensitivity, $S_{I}$. The values for $p_{G}, E G P_{b}$ and $n_{I}$ are 0.006 [1/min], $1.16[\mathrm{mmol} / \mathrm{min}]$ and $0.003[1 / \mathrm{min}]$ respectively. These sensitivity study results suggest $n_{K}, n_{L}, n_{C}$ and $\alpha_{G}$ can be fixed at their current population values without over simplifying the model. However, $\alpha_{G}$ does produce a notable shift in insulin sensitivity, $S_{I}$ as expected, given their trade-off relationship mathematically. A previous study showed changes in $\alpha_{G}$ produce a magnification in insulin sensitivity $S_{I}$ without compromising model performance unless it approaches non-physiological levels [79]. 

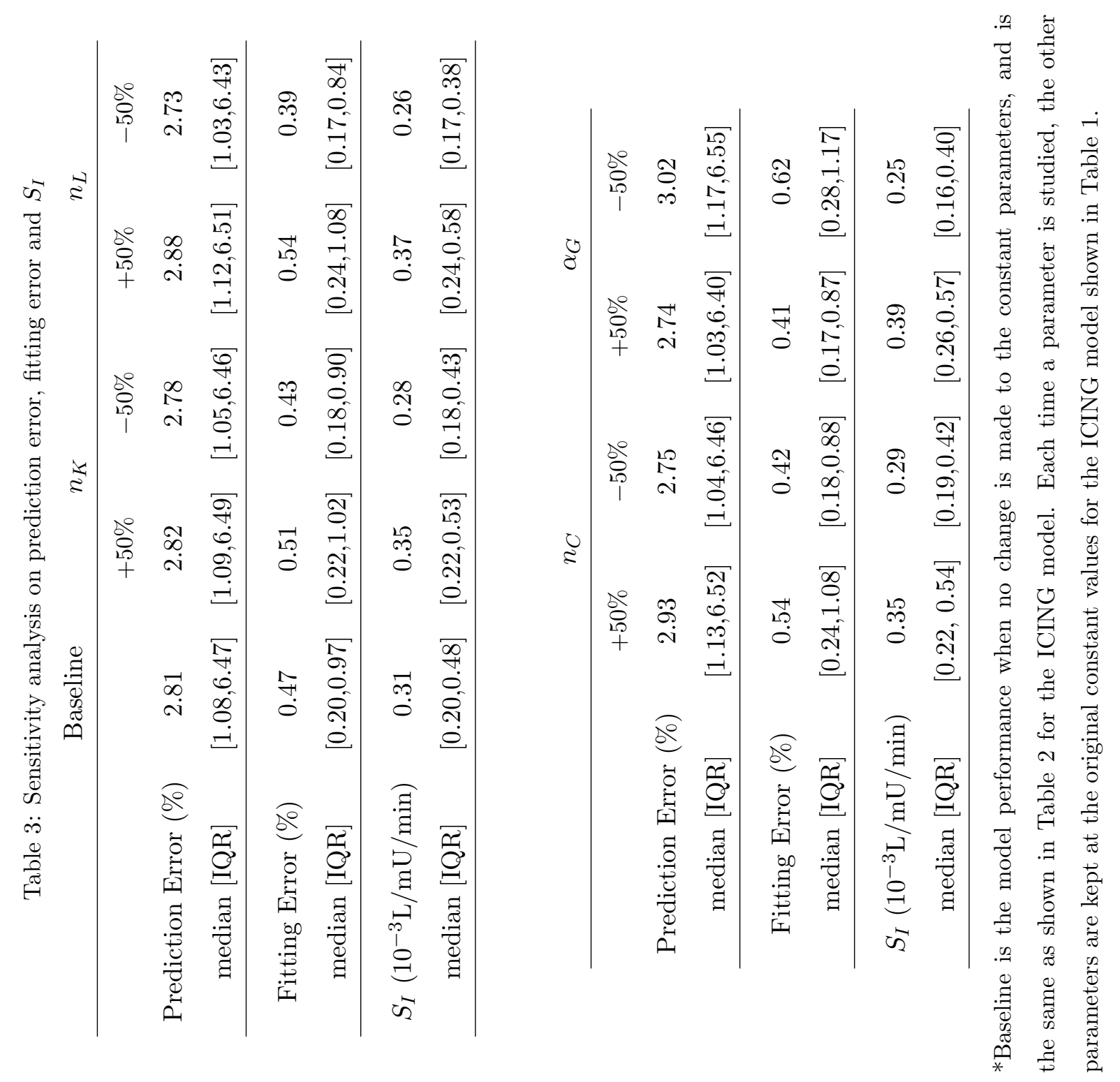


\section{Discussion}

The new ICING model presented in this study is an integration and improvement of two clinically validated glucose-insulin physiological models $[27,38]$. This new model has more explicit physiological relevance without increasing the number of patient-specific parameters to be identified. In particular, the insulin kinetics is expressed with distinctive routes for insulin clearance and transport from plasma, which reflects biological mechanisms. A more realistic model for gastric glucose absorption accounting for the stomach, gut and saturable glucose appearance is also introduced.

Parameters for endogenous glucose removal $p_{G}$, and basal endogenous glucose production $E G P_{b}$ trade off each other. Therefore, it is important that they are identified as a pair. The definition for $E G P_{b}$ implies this parameter stays constant for any given patient. The decision to keep $p_{G}$ as a constant is based on its relatively constant behaviour in ICU patients [39]. Grid analysis for the identification of $p_{G}$ and $E G P_{b}$ as constants population parameters found the most suitable combination of parameter values in reported physiological ranges [32, 48, 74, 76].

Many models have tried to include an estimated time-varying function for endogenous glucose production, typically for use in experimental tracer studies [80, 81, 82, 83]. Others developed functions based on study data $[34,84,85,86,87]$. In reality, tracer studies require different assumptions depending on experimental settings, and results are highly variable between individuals and influenced by different conditions [75, 88, 89, 90, 91, 92]. This study uses a basal endogenous glucose production $E G P_{b}$ as a constant in the mathematical model. This choice allows the variation in actual endogenous 
glucose production be described by combining $E G P_{b}$, variable suppression via $p_{G}$ and $G$, and also $S_{I}$ and $I$. More importantly, this approach allows $S_{I}$ be uniquely identified given the available data is limited to 1-2 hourly BG measurements. The value for $p_{G}$ found in this study is somewhat at the lower end of the range found in other studies [32, 76, 77, 78]. It is suspected for hyperglycaemic ICU patients that the suppression of EGP by plasma glucose levels is minimized compared to otherwise healthy subjects, which has been reported elsewhere due to high levels of circulating catecholamines, thus reducing the suppression of $E G P$ from elevated $G$ and $I$ [2, 3, 93, 94, 95].

Glucose uptake is strongly correlated with interstitial insulin [96]. However, interstitial insulin concentrations and dynamics are difficult or impossible to measure experimentally. This study attempted to find a realistic description of interstitial insulin by linking plasma insulin and BG response through known biological mechanisms and parameter identification. The diffusion rate between plasma and the interstitial space $n_{I}$, was identified as the critical parameter, and its population value is chosen using grid search. The identified optimal parameter value provided low fitting and prediction error in BG and particularly reduced inter-patient variability in prediction error.

"Effective" insulin half lives have been reported to be between 25-130 mins ( $k$ in Equation (16) or $n_{I}+n_{C}$ in Equation (17) to be between 0.0277$\left.0.0053 \mathrm{~min}^{-1}\right)[31,97,98]$. The value for $k$ in the Critical Care Model was $0.0198 \mathrm{~min}^{-1}$, which corresponds to a interstitial half life of 35 mins. The value for $n_{I}+n_{C}$ in the ICING model is 0.006 since $n_{I}=n_{C}=0.003 \mathrm{~min}^{-1}$, and correspond to a half life of 115.5 mins. The half lives from both models, 
although both within the reported ranges, were on the opposite ends of the spectrum. However, when $k$ was chosen for the Critical Care Model, clinical data were limited for its optimization $[27,36,44]$. The grid search on $n_{I}$ performed in this study clearly optimized this value for model performance using currently available data.

The value for $n_{I}$ identified for the new model is very low compared to that of Lotz et al. [38, 70] (0.003 v.s. $\left.\sim 0.0476 \mathrm{~min}^{-1}\right)$. Lotz et al. [38, 70] used a method to calculate $n_{I}$ adopted from Van Cauter et al. [54]. This method estimates $n_{I}$ from an individual's age, sex, weight, BSA, BMI and diagnosis of type 2 diabetes, developed using a model for C-peptide and its measurements. However, the $n_{I}$ population value calculated using this method fails to capture long term blood glucose-insulin dynamics. Specifically, insulin "pooling" and delayed utilization effects have been observed in critically ill patients by Doran et al. [47, 99]. With $n_{I}$ at such a high value, these features are lost from the model because the modeled insulin degradation is too fast. Note that given $n_{I}=n_{C}=0.0476 \mathrm{~min}^{-1}$, the interstitial half life of insulin from Lotz et al. [38] is more than 3 times shorter than the shortest reported time.

The discrepancy between $n_{I}$ found in this study and Lotz el al. [38] may have several explanations. These explanations include inherently different plasma-interstitium diffusion rates under critical illness and insulin diffusion across barrier being a saturable process. The latter possibility arises because the experimental diffusion rates are determined by using C-peptide measurements. Although C-peptide has very similar molecular properties to insulin, it does not go through a high and variable degree of first pass extraction in 
the portal vein [54]. Therefore its concentration is several folds higher than insulin in plasma. If the diffusion process is to any level saturable [50], the rates determined using C-peptide measurements will not be reflective of insulin. In addition, the plasma concentration achieved in critically ill patients is very different to that in EIC experiments or otherwise healthy diabetic individuals. Patients in [70] were subjected to an overnight fast. Hence, their plasma concentrations are relatively low and diffusion rates are faster for the short, very low insulin dose tests used in that research. In contrast, critically ill patients are often hyperinsulinaemic and infused with large amount of insulin. These ideas need to be further investigated with more insulin and C-peptide studies.

A further important issue addressed throughout this study is model identifiability. Given the limited data available, it is crucial to maintain a model that is uniquely identifiable with bedside (glucose) measurements. Although the model presented in this study requires many population assumptions, and resulted in a much simpler structure compared to many others $[33,34,35,100]$, it is able to accurately capture the highly dynamic response in critical illness. It is the authors' conclusion that given limited data in a noisy and highly variable environment, such as critical care, a model that requires the minimal number of parameters to be identified will potentially cope most successfully both mathematically and clinically. Given all the parameters kept as population constants have been carefully studied and their sensitivity analysed, this paper presents a clinically applicable yet comprehensive glucose-insulin model that is uniquely identifiable for each patient at any given time. The low, and more importantly tightly distributed, pre- 
diction errors, where few fail to be within the clinical measurement error of $7-12 \%[13,27]$, indicates the model is well suited for use in real-time, patient-specific TGC.

However, all models have limitations and this model would benefit from further investigation into some parameters. The critical parameters are those that influence the shape of $Q /\left(1+\alpha_{G} Q\right)$, as this level is the ultimate unknown (being unmeasurable) and the critical link between insulin and BG response. These parameters are effectively $n_{I}$ and $\alpha_{G}$, as the parameters that only appear in the plasma insulin equation (Equation (11)) can be more readily identified given insulin and C-peptide measurements. Simulation studies had been carried out to investigate the impact of these parameters, namely "effective" insulin half life and insulin-stimulated glucose removal saturation $[44,79]$. Both variables have direct impact on $S_{I}$. However, given that both parameters are kept in reported range of physiological levels, their variation simply creates a shift or magnification in the identified $S_{I}$ profiles and do not compromise model fitting or prediction performance. Ultimately, it is the control, or prediction performance, that is the most critical for a model designed for model-based therapeutics.

\section{Conclusions}

A new, more comprehensive glucose-insulin model is presented and validated using data from critically ill patients. The model is capable of accurately capturing long term dynamics and evolution of a critically ill patient's glucose-insulin response. Insulin sensitivity $S_{I}$ is the only parameter that is identified hourly for each individual. Its identification is guaranteed 
to be unique given the integral fitting method used in this study. Population constant parameters $p_{G}, E G P_{b}$ and $n_{I}$ have been identified in steps to avoid model identifiability issues. Parameter sensitivity analysis further confirms the validity of limiting time-varying parameters to $S_{I}$ only. The model achieved low fitting and, most importantly, low prediction error when fitted to blood glucose data from critically ill patients. Fitting errors and the $75^{\text {th }}$ percentile prediction errors were all well below measurement error for 173 patient and 42,941 hours of data. The new model outperforms its critical care predecessors, and has greater physiological relevance and more detailed insulin kinetics. This model therefore offers a platform to develop robust insulin therapies for tight glycaemic control.

\section{References}

[1] G. Van Den Berghe, P. Wouters, F. Weekers, C. Verwaest, F. Bruyninckx, M. Schetz, D. Vlasselaers, P. Ferdinande, P. Lauwers, R. Bouillon, Intensive insulin therapy in the critically ill patients, The New England Journal of Medicine 345 (19) (2001) 1359-67.

[2] B. Bistrian, Hyperglycemia and Infection: Which is the Chicken and Which is the Egg?, J Parenter Enteral Nutr 25 (4) (2001) 180-181.

[3] K. McCowen, C. Friel, J. Sternberg, S. Chan, R. Forse, P. Burke, B. Bistrian, Hypocaloric total parenteral nutrition: effectiveness in prevention of hyperglycemia and infectious complications-a randomized clinical trial, Crit Care Med 28 (11) (2000) 3606-11.

[4] M. J. Schultz, M. J. de Graaff, M. A. Kuiper, P. E. Spronk, The 
new Surviving Sepsis Campaign recommendations on glucose control should be reconsidered, Intensive Care Med 34 (4) (2008) 779-80, doi: 10.1007/s00134-008-1027-6.

[5] G. Van Den Berghe, A. Wilmer, I. Milants, P. J. Wouters, B. Bouckaert, F. Bruyninckx, R. Bouillon, M. Schetz, Intensive insulin therapy in mixed medical/surgical intensive care units: benefit versus harm, Diabetes 55 (11) (2006) 3151-9, doi:10.2337/db06-0855.

[6] J.-C. Preiser, NICE-SUGAR: the end of a sweet dream?, Critical Care 13 (3) (2009) 143, doi:10.1186/cc7790.

[7] P. Kalfon, J.-C. Preiser, Tight glucose control: should we move from intensive insulin therapy alone to modulation of insulin and nutritional inputs?, Critical Care 12 (3) (2008) 156, doi:10.1186/cc6915.

[8] J.-C. Preiser, P. Devos, Clinical experience with tight glucose control by intensive insulin therapy, Critical Care Medicine 35 (9 Suppl) (2007) S503-7, doi:10.1097/01.CCM.0000278046.24345.C7.

[9] J. G. Chase, G. M. Shaw, Is there more to glycaemic control than meets the eye?, Critical Care 11 (4) (2007) 160, doi:10.1186/cc6099.

[10] I. Vanhorebeek, L. Langouche, G. Van Den Berghe, Tight blood glucose control: What is the evidence?, Critical Care Medicine 35 (Suppl) (2007) S496-S502, doi:10.1097/01.CCM.0000278051.48643.91.

[11] E. S. Moghissi, M. T. Korytkowski, M. DiNardo, D. Einhorn, R. Hellman, I. B. Hirsch, S. E. Inzucchi, F. Ismail-Beigi, M. S. Kirkman, 
G. E. Umpierrez, American Association of Clinical Endocrinologists and American Diabetes Association consensus statement on inpatient glycemic control, Endocr Practice 15 (4) (2009) 353-69.

[12] G. Van Den Berghe, A. Wilmer, G. Hermans, W. Meersseman, P. J. Wouters, I. Milants, E. V. Wijngaerden, H. Bobbaers, R. Bouillon, Intensive insulin therapy in the medical ICU, The New England Journal of Medicine 354 (5) (2006) 449-61, doi:10.1056/NEJMoa052521.

[13] J. Chase, G. Shaw, A. J. Le Compte, T. Lonergan, M. Willacy, X. Wong, J. Lin, T. Lotz, D. Lee, C. E. Hann, Implementation and evaluation of the SPRINT protocol for tight glycaemic control in critically ill patients: a clinical practice change, Crit Care 12 (2) (2008) R49, doi:10.1186/cc6868.

[14] J. S. Krinsley, Effect of an intensive glucose management protocol on the mortality of critically ill adult patients, Mayo Clin Proc 79 (8) (2004) 992-1000.

[15] The NICE-SUGAR Study Investigators, Intensive versus Conventional Glucose Control in Critically Ill Patients, The New England Journal of Medicine 360 (13) (2009) 1283-97, doi:10.1056/NEJMoa0810625.

[16] R. Shulman, S. J. Finney, C. O’Sullivan, P. A. Glynne, R. Greene, Tight glycaemic control: a prospective observational study of a computerised decision-supported intensive insulin therapy protocol, Critical Care 11 (4) (2007) R75, doi:10.1186/cc5964. 
[17] F. M. Brunkhorst, C. Engel, F. Bloos, A. Meier-Hellmann, M. Ragaller, N. Weiler, O. Moerer, M. Gruendling, M. Oppert, S. Grond, D. Olthoff, U. Jaschinski, S. John, R. Rossaint, T. Welte, M. Schaefer, P. Kern, E. Kuhnt, M. Kiehntopf, C. Hartog, C. Natanson, M. Loeffler, K. Reinhart, for the German Competence Network Sepsis (SepNet), Intensive insulin therapy and pentastarch resuscitation in severe sepsis, The New England Journal of Medicine 358 (2) (2008) 125-39, doi:10.1056/NEJMoa070716.

[18] G. De La Rosa, J. Donado, A. Restrepo, A. Quintero, L. González, N. Saldarriaga, M. Bedoya, J. Toro, J. Velásquez, J. Valencia, C. Arango, P. Aleman, E. Vasquez, J. Chavarriaga, A. Yepes, W. Pulido, C. Cadavid, Grupo de Investigacion en Cuidado intensivo: GICI-HPTU, Strict glycaemic control in patients hospitalised in a mixed medical and surgical intensive care unit: a randomised clinical trial, Critical Care 12 (5) (2008) R120, doi:10.1186/cc7017.

[19] R. S. Wiener, D. C. Wiener, R. J. Larson, Benefits and risks of tight glucose control in critically ill adults: a meta-analysis, JAMA 300 (8) (2008) 933-44, doi:10.1001/jama.300.8.933.

[20] M. Treggiari, V. Karir, N. Yanez, N. Weiss, Intensive insulin therapy and mortality in critically ill patients, Crit Care 12 (1) (2008) R29.

[21] D. E. G. Griesdale, R. J. de Souza, R. M. van Dam, D. K. Heyland, D. J. Cook, A. Malhotra, R. Dhaliwal, W. R. Henderson, D. R. Chittock, S. Finfer, D. Talmor, Intensive insulin therapy and mortality among 
critically ill patients: a meta-analysis including NICE-SUGAR study data, CMAJ 180 (8) (2009) 821-7, doi:10.1503/cmaj.090206.

[22] M. Brownlee, Biochemistry and molecular cell biology of diabetic complications, Nature 414 (6865) (2001) 813-20, doi:10.1038/414813a.

[23] I. Hirsch, M. Brownlee, Should minimal blood glucose variability become the gold standard of glycemic control?, J Diabetes Complications 19 (3) (2005) 178-81.

[24] M. Egi, R. Bellomo, E. Stachowski, C. French, G. Hart, Variability of blood glucose concentration and short-term mortality in critically ill patients, Anesthesiology 105 (2) (2006) 244-52.

[25] J. G. Chase, S. Andreassen, K. Jensen, G. M. Shaw, Impact of human factors on clinical protocol performance: a proposed assessment framework and case examples, Journal of Diabetes Science and Technology 2 (3) (2008) 409-16.

[26] D. Aragon, Evaluation of nursing work effort and perceptions about blood glucose testing in tight glycemic control, Am J Crit Care 15 (4) (2006) 370-7.

[27] J. G. Chase, G. M. Shaw, T. Lotz, A. J. Le Compte, J. Wong, J. Lin, T. Lonergan, M. Willacy, C. E. Hann, Model-based insulin and nutrition administration for tight glycaemic control in critical care, Current Drug Delivery 4 (4) (2007) 283-96. 
[28] J. G. Chase, G. Shaw, X. Wong, T. Lotz, J. Lin, C. E. Hann, Modelbased Glycaemic Control in Critical Care - A review of the state of the possible, Biomedical Signal Processing \& Control 1 (1) (2006) 3-21.

[29] R. Hovorka, J. Kremen, J. Blaha, M. Matias, K. Anderlova, L. Bosanska, T. Roubicek, M. E. Wilinska, L. J. Chassin, S. Svacina, M. Haluzik, Blood glucose control by a model predictive control algorithm with variable sampling rate versus a routine glucose management protocol in cardiac surgery patients: a randomized controlled trial, The Journal of Clinical Endocrinology and Metabolism 92 (8) (2007) 2960-4, doi:10.1210/jc.2007-0434.

[30] A. Le Compte, J. G. Chase, A. Lynn, C. E. Hann, G. Shaw, X.-W. Wong, J. Lin, Blood Glucose Controller for Neonatal Intensive Care: Virtual Trials Development and First Clinical Trials, Journal of Diabetes Science and Technology 3 (5) (2009) 1066-1081.

[31] A. Mari, A. Valerio, A Circulatory Model for the Estimation of Insulin Sensitivity, Control Eng Practice 5 (12) (1997) 1747-1752.

[32] R. Bergman, L. Phillips, C. Cobelli, Physiologic evaluation of factors controlling glucose tolerance in man: measurement of insulin sensitivity and beta-cell glucose sensitivity from the response to intravenous glucose, J Clin Invest 68 (6) (1981) 1456-1467.

[33] R. S. Parker, F. J. Doyle, Control-relevant modeling in drug delivery, Advanced Drug Delivery Reviews 48 (2-3) (2001) 211-28. 
[34] R. Hovorka, L. J. Chassin, M. Ellmerer, J. Plank, M. E. Wilinska, A simulation model of glucose regulation in the critically ill, Physiological Measurement 29 (8) (2008) 959-78, doi:10.1088/0967-3334/29/8/008.

[35] R. Hovorka, L. J. Chassin, M. E. Wilinska, V. Canonico, J. A. Akwi, M. O. Federici, M. Massi-Benedetti, I. Hutzli, C. Zaugg, H. Kaufmann, M. Both, T. Vering, H. C. Schaller, L. Schaupp, M. Bodenlenz, T. R. Pieber, Closing the loop: the adicol experience, Diabetes Technology \& Therapeutics 6 (3) (2004) 307-18, doi:10.1089/1520915047744197990.

[36] X. Wong, I. Singh-Levett, L. Hollingsworth, G. Shaw, C. E. Hann, T. Lotz, J. Lin, O. Wong, J. G. Chase, A novel, model-based insulin and nutrition delivery controller for glycemic regulation in critically ill patients, Diabetes Technol Ther 8 (2) (2006) 174-90.

[37] J. Lin, D. Lee, J. G. Chase, G. M. Shaw, A. J. Le Compte, T. Lotz, J. Wong, T. Lonergan, C. E. Hann, Stochastic modelling of insulin sensitivity and adaptive glycemic control for critical care, Computer Methods and Programs in Biomedicine 89 (2) (2008) 141-52, doi: 10.1016/j.cmpb.2007.04.006.

[38] T. F. Lotz, J. G. Chase, K. A. McAuley, G. M. Shaw, X.-W. Wong, J. Lin, A. J. Le Compte, C. E. Hann, J. I. Mann, Monte Carlo analysis of a new model-based method for insulin sensitivity testing, Computer Methods and Programs in Biomedicine 89 (3) (2008) 215-25, doi:10.1016/j.cmpb.2007.03.007.

[39] C. E. Hann, J. G. Chase, J. Lin, T. Lotz, C. V. Doran, G. M. 
Shaw, Integral-based parameter identification for long-term dynamic verification of a glucose-insulin system model, Computer Methods and Programs in Biomedicine 77 (3) (2005) 259-70, doi: 10.1016/j.cmpb.2004.10.006.

[40] J. Lin, D. Lee, J. Chase, G. Shaw, C. E. Hann, T. Lotz, J. Wong, Stochastic modelling of insulin sensitivity variability in critical care, Biomedical Signal Processing and Control 1 (3) (2006) 229-242, doi: 10.1016/j.bspc.2006.09.003.

[41] T. Lotz, J. G. Chase, K. McAuley, D. Lee, J. Lin, C. E. Hann, J. Mann, Transient and steady-state euglycemic clamp validation of a model for glycemic control and insulin sensitivity testing, Diabetes Technology and Therapeutics 8 (3) (2006) 338-46.

[42] T. Lotz, U. Göltenbott, J. G. Chase, P. Docherty, C. E. Hann, A minimal C-peptide sampling method to capture peak and total prehepatic insulin secretion in model-based experimental insulin sensitivity studies, Journal of Diabetes Science and Technology 3 (4) (2009) 875-86.

[43] P. D. Docherty, J. G. Chase, T. Lotz, C. E. Hann, G. M. Shaw, J. Berkeley, J. I. Mann, K. A. McAuley, DISTq: An iterative analysis of glucose data for low-cost, real-time and accurate estimation of insulin sensitivity, The Open Medical Informatics Journal 3 (2009) 65-76, ISSN 1874-4311.

[44] J. G. Chase, G. Shaw, J. Lin, C. Doran, C. E. Hann, M. Robertson, P. Browne, T. Lotz, G. Wake, B. Broughton, Adaptive bolus-based 
targeted glucose regulation of hyperglycaemia in critical care, Med Eng Phys 27 (1) (2005) 1-11.

[45] T. Lonergan, A. J. Le Compte, M. Willacy, J. G. Chase, G. M. Shaw, X.-W. Wong, T. Lotz, J. Lin, C. E. Hann, A simple insulin-nutrition protocol for tight glycemic control in critical illness: development and protocol comparison, Diabetes Technol Ther 8 (2) (2006) 191-206, doi: 10.1089/dia.2006.8.191.

[46] T. Lonergan, A. J. Le Compte, M. Willacy, J. G. Chase, G. M. Shaw, X.-W. Wong, T. Lotz, J. Lin, C. E. Hann, A Pilot Study of the SPRINT Protocol for Tight Glycaemic Control in Critically Ill Patients, Diabetes Technology and Therapheutics 8 (4) (2006) 449-462.

[47] C. Doran, N. Hudson, K. Moorhead, J. G. Chase, G. Shaw, C. E. Hann, Derivative weighted active insulin control modelling and clinical trials for ICU patients, Med Eng Phys 26 (10) (2004) 855-66.

[48] A. Blakemore, S.-H. Wang, A. J. Le Compte, G. M. Shaw, X.-W. Wong, J. Lin, T. Lotz, C. E. Hann, J. G. Chase, Model-Based Insulin Sensitivity as a Sepsis Diagnostic in Critical Care, Journal of Diabetes Science and Technology 2 (3) (2008) 468-177.

[49] J. Chase, S. Andreassen, U. Pielmeier, C. E. Hann, K. McAuley, J. Mann, A glucose-insulin pharmacodynamic surface modeling validation and comparison of metabolic system models, Biomedical Signal Processing and Control 4 (4) (2009) 355-363. 
[50] B. Thorsteinsson, Kinetic models for insulin disappearance from plasma in man, Dan Med Bull 37 (2) (1990) 143-53.

[51] E. Ferrannini, C. Cobelli, The kinetics of insulin in man. II. Role of the liver, Diabetes Metab Rev 3 (2) (1987) 365-97.

[52] E. Ferrannini, C. Cobelli, The kinetics of insulin in man. I. General aspects, Diabetes Metab Rev 3 (2) (1987) 335-63.

[53] G. Toffolo, M. Campioni, R. Basu, R. Rizza, C. Cobelli, A minimal model of insulin secretion and kinetics to assess hepatic insulin extraction, Am J Physiol Endocrinol Metab 290 (1) (2006) E169-E176.

[54] E. Van Cauter, F. Mestrez, J. Sturis, K. Polonsky, Estimation of insulin secretion rates from C-peptide levels. Comparison of individual and standard kinetic parameters for C-peptide clearance, Diabetes 41 (3) (1992) 368-77.

[55] X.-W. Wong, J. G. Chase, C. E. Hann, T. F. Lotz, J. Lin, A. J. Le Compte, G. M. Shaw, Development of a Clinical Type 1 Diabetes Metabolic System Model and in Silico Simulation Tool, Journal of Diabetes Science and Technology 2 (3) (2008) 424-435.

[56] S. G. Hasselbalch, G. M. Knudsen, C. Videbaek, L. H. Pinborg, J. F. Schmidt, S. Holm, O. B. Paulson, No effect of insulin on glucose bloodbrain barrier transport and cerebral metabolism in humans, Diabetes 48 (10) (1999) 1915-21.

[57] S. G. Hasselbalch, P. L. Madsen, G. M. Knudsen, S. Holm, O. B. Paulson, Calculation of the FDG lumped constant by simultaneous 
measurements of global glucose and FDG metabolism in humans, J Cereb Blood Flow Metab 18 (2) (1998) 154-60.

[58] S. G. Hasselbalch, P. L. Madsen, L. P. Hageman, K. S. Olsen, N. Justesen, S. Holm, O. B. Paulson, Changes in cerebral blood flow and carbohydrate metabolism during acute hyperketonemia, Am J Physiol 270 (5 Pt 1) (1996) E746-51.

[59] A. D. Baron, G. Brechtel, P. Wallace, S. V. Edelman, Rates and tissue sites of non-insulin- and insulin-mediated glucose uptake in humans, Am J Physiol 255 (6 Pt 1) (1988) E769-74.

[60] H. Takeshita, Y. Okuda, A. Sari, The effects of ketamine on cerebral circulation and metabolism in man, Anesthesiology 36 (1) (1972) 6975.

[61] P. J. Cohen, S. C. Alexander, T. C. Smith, M. Reivich, H. Wollman, Effects of hypoxia and normocarbia on cerebral blood flow and metabolism in conscious man, Journal of Applied Physiology 23 (2) (1967) 183-9.

[62] G. Strauss, K. Moller, F. Larsen, J. Kondrup, G. M. Knudsen, Cerebral glucose and oxygen metabolism in patients with fulminant hepatic failure, Liver Transplantation 9 (12) (2003) 1244-1252.

[63] N. Hattori, S.-C. Huang, H.-M. Wu, E. Yeh, T. C. Glenn, P. M. Vespa, D. McArthur, M. E. Phelps, D. A. Hovda, M. Bergsneider, Correlation of Regional Metabolic Rates of Glucose with Glasgow Coma Scale After Traumatic Brain Injury, J Nucl Med 44 (11) (2003) 1709-16. 
[64] E. M. Bingham, D. Hopkins, D. Smith, A. Pernet, W. Hallett, L. Reed, P. K. Marsden, S. A. Amiel, The role of insulin in human brain glucose metabolism: an 18fluoro-deoxyglucose positron emission tomography study, Diabetes 51 (12) (2002) 3384-90.

[65] A. M. McCarthy, J. S. Elmendorf, GLUT4's itinerary in health \& disease, Indian J Med Res 125 (3) (2007) 373-88.

[66] L. J. Foster, A. Klip, Mechanism and regulation of GLUT-4 vesicle fusion in muscle and fat cells, Am J Physiol, Cell Physiol 279 (4) (2000) C877-90.

[67] N. J. Bryant, R. Govers, D. E. James, Regulated transport of the glucose transporter GLUT4, Nat Rev Mol Cell Biol 3 (4) (2002) 26777, doi:10.1038/nrm782.

[68] S. K. Andersen, J. Gjedsted, C. Christiansen, E. Tønnesen, The roles of insulin and hyperglycemia in sepsis pathogenesis, Journal of Leukocyte Biology 75 (3) (2004) 413-21, doi:10.1189/jlb.0503195.

[69] W. C. Duckworth, R. G. Bennett, F. G. Hamel, Insulin degradation: progress and potential, Endocr Rev 19 (5) (1998) 608-24.

[70] T. Lotz, High Resolution Clinical Model-Based Assessment of Insulin Sensitivity, PhD Thesis, Mechanical Engineering, University of Canterbury, Christchurch, New Zealand .

[71] S. Gudbjörnsdóttir, M. Sjöstrand, L. Strindberg, J. Wahren, P. Lönnroth, Direct measurements of the permeability surface area for 
insulin and glucose in human skeletal muscle, The Journal of Clinical Endocrinology and Metabolism 88 (10) (2003) 4559-64.

[72] M. Sjöstrand, A. Holmäng, P. Lönnroth, Measurement of interstitial insulin in human muscle, Am J Physiol 276 (1 Pt 1) (1999) E151-4.

[73] M. Sjostrand, A. Holmang, L. Strindberg, P. Lonnroth, Estimations of muscle interstitial insulin, glucose, and lactate in type 2 diabetic subjects, Am J Physiol Endocrinol Metab 279 (5) (2000) E1097-103.

[74] L. Tappy, M. Berger, J. M. Schwarz, M. McCamish, J. P. Revelly, P. Schneiter, E. Jéquier, R. Chioléro, Hepatic and peripheral glucose metabolism in intensive care patients receiving continuous high- or lowcarbohydrate enteral nutrition, JPEN Journal of parenteral and enteral nutrition 23 (5) (1999) 260-7.

[75] C. Chambrier, M. Laville, R. B. K, M. Odeon, P. Boulétreau, M. Beylot, Insulin sensitivity of glucose and fat metabolism in severe sepsis, Clin Sci 99 (4) (2000) 321-8.

[76] C. Cobelli, A. Caumo, M. Omenetto, Minimal model SG overestimation and SI underestimation: improved accuracy by a Bayesian twocompartment model, Am J Physiol 277 (3 Pt 1) (1999) E481-488.

[77] C. McDonald, A. Dunaif, D. Finegood, Minimal-model estimates of insulin sensitivity are insensitive to errors in glucose effectiveness, J Clin Endocrinol Metab 85 (7) (2000) 2504-2508.

[78] G. Pillonetto, G. Sparacino, P. Magni, R. Bellazzi, C. Cobelli, Minimal model $S_{I}=0$ problem in NIDDM subjects: nonzero Bayesian estimates 
with credible confidence intervals, Am J Physiol Endocrinol Metab 282 (3) (2002) E564-573.

[79] J. G. Chase, G. M. Shaw, J. Lin, C. V. Doran, M. Bloomfield, G. C. Wake, B. Broughton, C. Hann, T. Lotz, Impact of Insulin-Stimulated Glucose Removal Saturation on Dynamic Modelling and Control of Hyperglycaemia, International Journal of Intelligent Systems Technologies and Applications (IJISTA) 1 (1/2) (2004) 79-94.

[80] C. Dalla Man, A. Caumo, R. Basu, R. Rizza, G. Toffolo, C. Cobelli, Minimal model estimation of glucose absorption and insulin sensitivity from oral test: validation with a tracer method, American Journal of Physiology-Endocrinology and Metabolism 287 (4) (2004) E637-E643.

[81] A. Avogaro, P. Vicini, A. Valerio, A. Caumo, C. Cobelli, The hot but not the cold minimal model allows precise assessment of insulin sensitivity in NIDDM subjects, Am J Physiol 270 (3 Pt 1) (1996) E53240.

[82] A. Caumo, C. Cobelli, Hepatic glucose production during the labeled IVGTT: estimation by deconvolution with a new minimal model, Am J Physiol 264 (5 Pt 1) (1993) E829-41.

[83] A. Mari, J. Wahren, R. A. DeFronzo, E. Ferrannini, Glucose absorption and production following oral glucose: comparison of compartmental and arteriovenous-difference methods, Metab Clin Exp 43 (11) (1994) 1419-25. 
[84] D. Araujo-Vilar, C. A. Rega-Liste, D. A. Garcia-Estevez, F. SarmientoEscalona, V. Mosquera-Tallon, J. Cabezas-Cerrato, Minimal model of glucose metabolism: modified equations and its application in the study of insulin sensitivity in obese subjects, Diabetes Research and Clinical Practice 39 (2) (1998) 129-41.

[85] U. Picchini, A. D. Gaetano, S. Panunzi, S. Ditlevsen, G. Mingrone, A mathematical model of the Euglycemic Hyperinsulinemic Clamp, Theor Biol Med Model 2 (2005) 44.

[86] E. Ruiz-Velázquez, R. Femat, D. Campos-Delgado, Blood glucose control for type I diabetes mellitus: A robust tracking $\mathrm{H} \infty$ problem, Control Engineering Practice 12 (2004) 1179-1195.

[87] H. E. Silber, P. M. Jauslin, N. Frey, R. Gieschke, U. S. H. Simonsson, M. O. Karlsson, An integrated model for glucose and insulin regulation in healthy volunteers and type 2 diabetic patients following intravenous glucose provocations, The Journal of Clinical Pharmacology 47 (9) (2007) 1159-71, doi:10.1177/0091270007304457.

[88] A. D. Cherrington, D. Edgerton, D. K. Sindelar, The direct and indirect effects of insulin on hepatic glucose production in vivo, Diabetologia 41 (9) (1998) 987-96.

[89] M. Mevorach, A. Giacca, Y. Aharon, M. Hawkins, H. Shamoon, L. Rossetti, Regulation of endogenous glucose production by glucose per se is impaired in Type 2 diabetes mellitus, The Journal of Clinical Investigation 102 (4) (1998) 744-753. 
[90] L. U. Monzillo, O. Hamdy, Evaluation of insulin sensitivity in clinical practice and in research settings, Nutr Rev 61 (12) (2003) 397-412.

[91] A. Cherrington, Banting Lecture 1997. Control of glucose uptake and release by the liver in vivo, Diabetes 48 (5) (1999) 1198-214.

[92] D. Elahi, G. Meneilly, K. Minaker, D. Andersen, J. Rowe, Escape of hepatic glucose production during hyperglycemic clamp, Am J Physiol 257 (5 Pt 1) (1989) E704-11.

[93] B. Mizock, Alterations in fuel metabolism in critical illness: hyperglycaemia, Best Pract Res Clin Endocrinol Metab 15 (4) (2001) 533-51.

[94] A. Thorell, O. Rooyackers, P. Myrenfors, M. Soop, J. Nygren, O. Ljungqvist, Intensive insulin treatment in critically ill trauma patients normalizes glucose by reducing endogenous glucose production, J Clin Endocrinol Metab 89 (11) (2004) 5382-6.

[95] K. M. Dungan, S. S. Braithwaite, J.-C. Preiser, Stress hyperglycaemia, Lancet 373 (9677) (2009) 1798-807.

[96] R. Poulin, G. Steil, D. Moore, M. Ader, R. Bergman, Dynamics of glucose production and uptake are more closely related to insulin in hindlimb lymph than in thoracic duct lymph., Diabetes 43 (2) (1994) $180(11)$.

[97] A. Natali, A. Gastaldelli, S. Camastra, A. Sironi, E. Toschi, A. Masoni, E. Ferrannini, A. Mari, Dose-response characteristics of insulin action on glucose metabolism: a non-steady-state approach, Am J Physiol Endocrinol Metab 278 (5) (2000) E794-801. 
[98] K. Turnheim, W. Waldhausl, Essentials of insulin pharmacokinetics, Wien Klin Wochenschr 100 (3) (1988) 65-72.

[99] C. Doran, J. G. Chase, G. Shaw, K. Moorhead, N. Hudson, Automated insulin infusion trials in the intensive care unit, Diabetes Technol Ther 6 (2) (2004) 155-65.

[100] R. S. Parker, F. J. Doyle, N. A. Peppas, The intravenous route to blood glucose control, IEEE engineering in medicine and biology magazine: the quarterly magazine of the Engineering in Medicine \& Biology Society 20 (1) (2001) 65-73. 